\title{
POST-STROKE EXECUTIVE FUNCTION IMPAIRMENTS IN RELATION TO WHITE MATTER DAMAGE DUE TO STROKE LESIONS VERSUS LEUKOARAIOSIS
}

Georgina Hobden, MSc ${ }^{1}$, Margaret Moore, DPhil ${ }^{1}$, Evangeline Grace Chiu ${ }^{1}$, MSc, Sarah Pendlebury, FRCP DPhil ${ }^{2,3}$, Nele Demeyere, $\mathrm{PhD}^{1}$

${ }^{1}$ Department of Experimental Psychology, University of Oxford, UK.

${ }^{2}$ Wolfson Centre for Prevention of Stroke and Dementia, Wolfson Building, Nuffield Department of Clinical Neurosciences, University of Oxford, UK.

${ }^{3}$ NIHR Oxford Biomedical Research Centre and Departments of General (Internal) Medicine and Geratology, John Radcliffe Hospital, Oxford, UK

\section{Corresponding author:}

Nele Demeyere

Department of Experimental Psychology,

Radcliffe Observatory Quarter,

Oxford,

OX2 6GG

United Kingdom

nele.demeyere@psy.ox.ac.uk

Cover title:

POST-STROKE EXECUTIVE FUNCTION 


\section{ABSTRACT}

\section{BACKGROUND}

There is a high prevalence of executive function impairments among stroke survivors. However, the underlying aetiology remains unclear. In particular, we address whether focal, stroke-specific white matter damage or diffuse comorbid white matter damage (leukoaraiosis) is more associated with executive function impairments.

\section{METHODS}

This project is a retrospective analysis of data collected within the Oxford Cognitive Screening programme. Patients were recruited in the acute stage of stroke if they had a confirmed diagnosis of stroke, were at least 18 years of age, were able to remain alert for 20 minutes, and were able to provide informed consent. Patients in the present analysis completed follow up neuropsychological assessment at six-months with the Oxford Cognitive Screen-Plus to assess executive function. Stroke lesions were manually delineated on acute clinical brain scans allowing us to quantify focal stroke-specific white matter damage using the HCP-842 tractography atlas. Leukoaraiosis was visually rated on clinical scans using the Age-Related White Matter Changes scale.

\section{RESULTS}

This study included data from 90 stroke patients (mean age $=73.76$ years; $47.78 \%$ female). Multiple linear regression analyses showed that the presence of leukoaraiosis predicted poorer executive functioning six-months after stroke $(B=-0.33, p=.031,95 \%$ CI [-0.64 0.03]). However, post-stroke executive functioning was not predicted by stroke-specific damage to white matter tracts.

\section{CONCLUSIONS}

Overall, these results provide novel insight into the neural substrates underlying post-stroke executive dysfunction and highlight the prognostic utility of using routine clinical CT scans to assess leukoaraiosis. 


\section{INTRODUCTION}

Stroke is the third most important cause of disability burden worldwide. ${ }^{1,2}$ Whilst stroke mortality rates have decreased due to improved acute care, ${ }^{3}$ there is a higher prevalence of chronic stroke survivors. ${ }^{4}$ Prevalence of post-stroke cognitive impairment is high $^{5}$ with in particular executive dysfunction estimated to affect between $19 \%$ and $75 \%$ of chronic stroke survivors. ${ }^{6,7,8}$ Post-stroke executive function impairment has been associated with reduced quality of life, ${ }^{9}$ disability in activities of daily living, ${ }^{10}$ and increased mortality. ${ }^{11}$

Post-stroke executive dysfunction has been linked to focal lesions affecting white matter pathways ${ }^{12}$ as well as diffuse leukoaraiosis, ${ }^{13,14}$ which affects $64-86 \%$ of stroke patients. ${ }^{15,16}$ However, previous studies have investigated the role of stroke-specific white matter damage or leukoaraiosis in isolation and have not studied how these conditions might interact in the same sample. Furthermore, the published studies yield comparatively ungeneralisable results due to their reliance on MRI, which is not suitable for a significant, non-random portion of the stroke population (e.g., patients with implants). ${ }^{17}$

This investigation aims to clarify the relative contributions of stroke-specific white matter damage and leukoaraiosis to post-stroke executive dysfunction using routine clinical CT brain scans from a representative sample of chronic stroke survivors.

\section{METHODS}

\section{Standard Protocol Approvals, Registrations, and Patient Consents}

This project represents a retrospective analysis of data collected within the Oxford Cognitive Screening (OCS) programme, ${ }^{18}$ which recruited stroke survivors during acute hospitalisation and conducted follow up neuropsychological assessments at six-months. The OCS 
medRxiv preprint doi: https://doi.org/10.1101/2021.11.12.21266247; this version posted November 14, 2021. The copyright holder for this

programme received NHS ethics approval (OCS-Tablet and OCS-Recovery studies, NHS RECs 14/LO/0648 and 18/SC/0550). All patients provided written or witnessed informed consent at recruitment and at follow up.

\section{Participants}

The OCS programme recruited a consecutive sample of stroke survivors and included all patients who had a confirmed diagnosis of acute stroke, were at least 18 years of age, were able to remain alert for 20 minutes, and were able to provide informed consent.

Patients were considered for inclusion in this investigation if they had completed the follow up assessment with the more detailed Oxford Cognitive Screen-Plus (OCS-Plus) ${ }^{19}$ executive function assessment at six-months after stroke $(n=185)$. Patients were excluded where no usable scan was available $(n=59)$; scan showed evidence of additional or different pathology $(n=3)$; OCS-Plus assessment was incomplete $(n=13)$; or multiple strokes were visible on scan $(n=20)$. Although patients with multiple, temporally distinct strokes could have been included in the leukoaraiosis analysis, the inclusion of these patients would complicate the interpretation of the focal white matter damage analyses. Therefore, these patients were excluded from both analyses so that cohorts were comparable, to facilitate informative comparisons of the relative contributions of focal lesions and leukoaraiosis to executive dysfunction. Demographic details of the resultant sample of 90 stroke survivors as reported by relevant medical records are presented in Table 1.

[Insert Table 1] 


\section{Cognitive data}

Executive function was assessed using the OCS-Plus, a tablet-based cognitive screen designed to provide fine-grained measures of memory and executive function. ${ }^{19}$ This tool has been validated versus standardised pen-and-paper neuropsychological assessments in a large, normative aging sample. ${ }^{19}$ The OCS-Plus is specifically designed to tap executive function subdomains with minimal interference from impairments within separate cognitive domains (e.g., language, memory). ${ }^{20}$ In total, the OCS-Plus takes approximately 25 minutes to complete. ${ }^{19}$ In the present investigation, data from the OCS-Plus Trails, Rule Finding, and Selection tasks were considered.

First, the OCS-Plus Trails Task measures set-switching and is a variation of standard pen-and-paper Trail Making Test. ${ }^{21}$ This task requires patients to connect a series of shapes according to specific rules (Supplementary Figure 1-1). In the final subtest, patients are required to connect both circles and squares in alternating order, connecting circles in decreasing order of size and squares in increasing order of size. Performance was evaluated by summing the number of correct connections made on this rule-switching condition (range $=0-14)$.

The OCS-Plus Rule Finding Task measures complex executive attention and is analogous to the Brixton Spatial Anticipation test, ${ }^{22}$ but can be administered more quickly and places lower demands on working memory. Patients are shown three columns of squares and triangles which regularly vary in luminosity (Supplementary Figure 1-2). A red dot is placed within a shape, then moves throughout the array according to a specific but changing spatial rule. Patients are instructed to learn the rule guiding the dot's movement and predict 
where the dot will appear next. Performance was scored based on the number of correct location predictions made (range $=0-46$ ).

Finally, the OCS-Plus Selection Task measures strategic search as well as working memory. Patients are allowed three minutes to identify and select all line drawings of fruits in a search matrix (Supplementary Figure 1-3). Patients are instructed to select each target stimulus once, whilst ignoring irrelevant distractors. Importantly, no visible record of previous responses is provided therefore making this analogous to "invisible cancellation" and loading spatial working memory as patients are required to keep track of previously found items. ${ }^{23}$ Performance was scored by summing the number of targets successfully identified (range $=0-30)$.

To attain an overall measure of executive functioning, individual performance on each of these three OCS-Plus task scores were z-score transformed using the data collected in this study, and the average $\mathrm{z}$-score was used to quantify overall executive functioning ability for each patient. This approach has the advantage that it encapsulates the unity and diversity of executive functioning subdomains (i.e., updating, inhibition, and shifting), ${ }^{24}$ in contrast to previous studies that considered performance on a single executive function test. ${ }^{12}$

\section{Lesion analyses}

Acute whole-brain CT data (slice thickness $5 \mathrm{~mm}$ ) were collected for each patient (range $=0$ 13 days post-stroke). Stroke lesions were manually delineated on native space scans by two trained and blinded researchers (GH and $\mathrm{MM}$ ) using the MRIcron software package (McCausland Center for Brain Imaging, Columbia, SC, USA). The resultant lesion masks were smoothed at $5 \mathrm{~mm}$ full width at half maximum in the z-direction and binarised using a 
threshold of 0.5. Scans and lesion masks were reoriented to the anterior commissure and warped into 1 x 1 x $1 \mathrm{~mm}$ stereotaxic space using the Statistical Parametric Mapping 12 and Clinical Toolbox. ${ }^{25}$ Normalised scans and lesion masks were visually inspected for quality. These binarised lesion masks were used to calculate stroke volume and white matter disconnection severity statistics.

Stroke-specific white matter damage was quantified in terms of white matter tract disconnection severities, which were estimated using a lesion quantification toolkit. ${ }^{26}$ This toolkit estimates tract-level disconnection for 70 canonical white matter tracts, as defined by the HCP-842 streamline tractography atlas, ${ }^{27}$ with the corpus callosum divided into five segments based on Freesurfer corpus callosum segmentation. The toolkit works by embedding the lesion into the $\mathrm{HCP}-842$ as a region of interest (ROI) and iteratively loading the streamline trajectories for each of the tracts. The files are filtered to retain only those streamlines that intersect the volume occupied by the lesion. For each tract, the percentage disconnection severity is calculated by converting the number of disconnected streamlines into a percentage of the total number of streamlines assigned to that tract. Given that anatomical homologues of some white matter ROIs exist within both hemispheres, this investigation calculated separate metrics for each of these homologues, then averaged across hemispheres to produce a single measure per patient for each ROI.

For statistical analysis, ROI disconnection was binarised as present (at least $10 \%$ disconnection) or absent (less than $10 \%$ disconnection) for each $\mathrm{ROI}^{26}$ The number of disconnected ROIs was then summed to create an overall measure of stroke-related white matter disconnection for each patient. 


\section{White matter ratings}

Leukoaraiosis as visualised on the clinical CT scans was evaluated using the Age-Related White Matter Changes visual rating scale (ARWMC scale) ${ }^{28}$ Visual ratings were assigned by a trained rater $(\mathrm{GH})$, who was blinded to behavioural results. Leukoaraiosis was assessed in five regions within each hemisphere (10 regions total): frontal, parieto-occipital, temporal, infratentorial, and basal ganglia. Each region was assigned a score of 0-3 according to the criteria in Supplementary Table 1. In cases where a brain region was severely affected by stroke damage so that leukoaraiosis could not be evaluated, the affected region was assigned the same score as the anatomically homologous region in the opposite hemisphere. A total score reflecting the severity of leukoaraiosis across the entire brain was calculated by summing the assigned scores across all ten regions (range $=0-30$ ). This total score was used to categorise leukoaraiosis as absent (0), mild (1-5), moderate $(6-10)$, or severe $(>10) .{ }^{29}$

\section{Statistical analysis}

Behavioural and clinical data were cleaned before analysis. Mean substitution was employed to impute missing values for patient age $(n=8)$, education $(n=39)$, and lesion volume $(n=$ 4). For all multiple linear regression analyses, residual plots were visually inspected to test the assumptions of linearity, normality of residuals, and homogeneity of residuals variance. Where appropriate, a 5\% false discovery rate correction was applied to correct for inflated false positive rates due to multiple comparisons. All regression analyses included age, sex, years of education, stroke type (ischaemic, haemorrhagic), stroke lateralisation (left, right, bilateral), stroke territory (anterior cerebral artery, middle cerebral artery, posterior cerebral artery, vertebrobasilar, intraventricular, multiple territories) and stroke volume as covariates of no interest. 
medRxiv preprint doi: https://doi.org/10.1101/2021.11.12.21266247; this version posted November 14, 2021. The copyright holder for this

First, a multiple linear regression analysis was conducted to investigate whether poststroke executive function is predicted by white matter tract disconnection severity due to focal stroke damage. In this analysis, the overall white matter disconnection score (number of ROIs with at least $10 \%$ disconnection) was included as a predictor variable. Next, a multiple linear regression was conducted to investigate whether post-stroke executive function is predicted by the presence of leukoaraiosis. Finally, we planned to conduct a multiple linear regression to investigate whether post-stroke executive function is better predicted by the presence of leukoaraiosis or by overall stroke-specific white matter tract disconnection severity. Full statistics for each conducted analysis are reported in Supplementary Materials. Overall, these analyses aimed to clarify whether post-stroke executive function is predicted by focal stroke-specific white matter damage and/or leukoaraiosis.

\section{Data Availability}

All data used in the analyses of the present study have been made openly available on the Open Science Framework (https://osf.io/r4h3m/).

\section{$\underline{\text { RESULTS }}$}

First, basic descriptive analyses were conducted to investigate data from the behavioural, lesion, and leukoaraiosis measures employed in this study. The mean scores for the OCS-Plus Trails, Rule Finding, and Selection tasks were $8.20(S D=4.35$, range $=0-14), 18.26(S D=$ 8.30 , range $=2-37)$, and $25.49(S D=5.28$, range $=3-30)$, respectively. Figure 1 shows the distribution of scores for these tasks, relative to the mean scores derived from normative data. $^{19}$ 


\section{[Insert Figure 1]}

Lesion anatomy was available for 86 patients because of four further exclusions for this analysis due to poor spatial normalisation of the lesion masks. Figure 2 presents a lesion overlay for these patients, demonstrating good coverage for this investigation's target ROIs. Table 2 shows the descriptive statistics for each included ROI, and also demonstrates a good level of lesion coverage across ROIs considered in the present investigation (Table 2). According to the overall stroke-specific white matter disconnection score, the average number of ROIs disconnected by at least $10 \%$ was $10.17(S D=8.70$, range $=0-34)$.

\section{[Insert Figure 2 here]}

\section{[Insert Table 2 here]}

Leukoaraiosis was categorised as absent, mild, moderate, or severe in 32, 35, 15, and 8 patients, respectively. Leukoaraiosis was also binarised as simply present $(n=58)$ or absent $(n=32)$ for some of the subsequent statistical analyses.

Next, the relationship between stroke-specific white matter ROI disconnection and executive function was analysed using the overall white matter disconnection score (number of ROIs disconnected by at least $10 \%$ ). The executive function score was not significantly predicted by the overall stroke-specific white matter disconnection measure $(B=0.00, p=$ $.784,95 \%$ CI [-0.02 0.03]), although age was a significant negative predictor of executive function at $p<.001$. To verify that this null result was not a consequence of quantifying white matter disconnection across multiple white matter tracts, further multiple linear regressions were conducted with individual ROI disconnections included as continuous 
predictor variables and binarised predictor variables. Even before correction for multiple comparisons, these analyses confirmed that executive function was not significantly predicted by stroke-specific disconnection of any individual white matter ROIs (see Supplementary Table 2).

Next, a linear regression was conducted to investigate the relationship between executive function score and the presence of leukoaraiosis. This model was found to be significant $\left(F(13,76)=4.24, p<.001, R^{2}=.42, R_{\text {Adjusted }}^{2}=.32.\right)$, with post-stroke executive function being significantly poorer in patients with leukoaraiosis, compared to patients without leukoaraiosis $(B=-0.33, p=.032,95 \%$ CI [-0.63 -0.03]). (Figure 3). Additionally, patient age $(B=-0.03, p<.001,95 \%$ CI $[-0.04-0.02])$ and the occurrence of a single stroke impacting multiple vascular territories versus a single vascular territory (anterior cerebral artery) $(B=-1.03, p=.027,95 \% \mathrm{CI}[-1.95,-0.12])$ were found to be significant predictors of lower executive function scores. No other covariates were found to be significant.

\section{[Insert Figure 3 here]}

\section{DISCUSSION}

The purpose of this study was to investigate the association between post-stroke executive functioning and both focal stroke-specific white matter damage and leukoaraiosis in a clinically representative sample of chronic stroke survivors. The presence of leukoaraiosis was found to be a significant predictor of reduced executive function scores, while strokespecific white matter damage was not. These findings provide novel insight into the neural substrates underlying post-stroke executive function impairments and demonstrate the prognostic utility of leukoaraiosis measures as reported by routinely collected CT scans. 
First, stroke-specific damage to white matter ROIs was not a significant predictor of executive functioning. This finding differs from previous studies that have linked executive function to specific white matter tracts..$^{30,31,32}$ In a voxel-lesion symptom mapping study, researchers identified an association between executive functioning and damage to both the superior longitudinal fasciculus and anterior corona in a sample of traumatic brain injury patients. ${ }^{33}$ However, the analysis did not control for lesion volume and only considered data from relatively young patients who would be less likely to exhibit age-related reductions in white matter integrity (leukoaraiosis) that may impair executive functioning. Previous stroke lesion-mapping studies have linked damage to the left superior longitudinal fasciculus with deficits on the Trail Making Tests. ${ }^{12}$ However, we note that traditional lesion-mapping approaches may not represent a valid methodology for investigating the correlates of diffuse, disconnection syndromes because lesion-mapping analyses tend to "average" locations of involved anatomy rather than accurately localising spatially distinct but equally critical structures. The present investigation avoided this issue by quantifying stroke-specific white matter damage using a ROI-based approach instead.

While stroke-specific white matter damage was not significantly associated with executive function after stroke, the presence of leukoaraiosis as reported by routinely collected CT scans was. This finding is critically important as it suggests that post-stroke executive dysfunction may not always be caused by patterns of localised stroke-specific damage, but instead may be linked to large-scale network integrity issues caused by white matter degeneration. The present investigation adds to previous studies ${ }^{13,14}$ by demonstrating that leukoaraiosis is not only a key predictor of executive dysfunction, but that it may act as a more informative measure than stroke-specific white matter damage. 
The findings of this study are also important to consider in the context of current methodological practices. Leukoaraiosis detected on CT is generally thought to represent an underestimation of white matter pathology. ${ }^{34,35}$ Although CT may indeed underestimate the spatial extent and severity of changes in white matter integrity, this investigation demonstrates that CT detects levels of leukoaraiosis that correlate meaningfully with poststroke cognitive outcome. CT-based measures should therefore be considered for use in research studies of white matter disease to ensure generalisability of findings to real-world populations, since restriction to MRI will result in substantial selection bias. Previous cohort studies have demonstrated that CT and MRI data can be harmonized to produce comparable ratings where one or other imaging modality has been used according to feasibility and tolerability. ${ }^{29,5}$ In addition, since $\mathrm{CT}$ is the most commonly used imaging method for routine clinical assessment of stroke, it is important to understand its prognostic value. Such data from CT-brain imaging could be incorporated into clinical risk prediction algorithms, particularly should automated assessment methods become available.

Several potential limitations are present within this study. First, any research aiming to link neuroanatomy to behavioural impairments must make a number of methodological choices that may ultimately bias results. ${ }^{36}$ For example, in this study, executive dysfunction was quantified by averaging performance across three standardised metrics. This approach aimed to provide a comprehensive assessment of executive function subdomains ${ }^{24}$ but independent assessment of subdomains may have generated different results. Similarly, leukoaraiosis was quantified using the ARWMC scale but alternative rating scales are available (e.g., Fazekas scale ${ }^{37}$ ), so future studies should assess whether our results can be replicated using other rating scales. 
Furthermore, this investigation combined acute imaging data with chronic behavioural data, which is not ideal because brain networks undergo substantial reorganisation and regeneration during stroke recovery due to neural plasticity. ${ }^{38}$ This cortical reorganisation may weaken statistical brain-behaviour relationships as patients who exhibited executive dysfunction at the acute stage may have recovered by the time of chronic assessment. Future investigations are needed to determine whether the results on the lack of relationship between executive function and the stroke-specific white matter damage found here generalise to patients in the acute stage post-stroke.

Overall, this investigation provides important insight into the neurological basis of post-stroke executive dysfunction. Specifically, the present study found that leukoaraiosis was associated with poorer executive functioning among a clinically representative sample of chronic stroke survivors, even though stroke-specific white matter damage was not. This observation demonstrates that pre-existing white matter pathology may well impact poststroke cognitive outcomes to a greater extent than any stroke-specific white matter damage.

\section{REFERENCES}

1. Lozano R, Naghavi M, Foreman K, et al. Global and regional mortality from 235 causes of death for 20 age groups in 1990 and 2010: A systematic analysis for the Global Burden of Disease Study 2010. The Lancet. 2012;380(9859):2095-2128.

doi:10.1016/S0140-6736(12)61728-0

2. Feigin VL, Forouzanfar MH, Krishnamurthi R, et al. Global and regional burden of stroke during 1990-2010: Findings from the Global Burden of Disease Study 2010. The Lancet. 2014;383(9913):245-255. doi:10.1016/S0140-6736(13)61953-4

3. Seminog OO, Scarborough P, Wright FL, Rayner M, Goldacre MJ. Determinants of the decline in mortality from acute stroke in England: Linked national database study of 795 869 adults. BMJ. 2019;365:11778. doi:10.1136/bmj.11778 
medRxiv preprint doi: https://doi.org/10.1101/2021.11.12.21266247; this version posted November 14, 2021. The copyright holder for this

4. Johnson CO, Nguyen M, Roth GA, et al. Global, regional, and national burden of stroke, 1990-2016: A systematic analysis for the Global Burden of Disease Study 2016. Lancet Neurol. 2019;18(5):439-458. doi:10.1016/S1474-4422(19)30034-1

5. Pendlebury ST, Rothwell PM. Incidence and prevalence of dementia associated with transient ischaemic attack and stroke: Analysis of the population-based Oxford Vascular Study. Lancet Neurol. 2019;18(3):248-258. doi:10.1016/S1474-4422(18)30442-3

6. Hurford R, Charidimou A, Fox Z, Cipolotti L, Werring DJ. Domain-specific trends in cognitive impairment after acute ischaemic stroke. J Neurol. 2013;260(1):237-241. doi:10.1007/s00415-012-6625-0

7. Lesniak M, Bak T, Czepiel W, Seniow J, Czlonkowska A. Frequency and prognostic value of cognitive disorders in stroke patients. Dement Geriatr Cogn Disord. 2008;26(4):356-363. doi:10.1159/000162262

8. Zinn S, Bosworth HB, Hoenig HM, Swartzwelder HS. Executive function deficits in acute stroke. Arch Phys Med Rehabil. 2007;88(2):173-180.

doi:10.1016/j.apmr.2006.11.015

9. Pohjasvaara T, Leskelä M, Vataja R, et al. Post-stroke depression, executive dysfunction and functional outcome. Eur J Neurol. 2002;9(3):269-275. doi:10.1046/j.1468-

1331.2002.00396.x

10. Mole JA, Demeyere N. The relationship between early post-stroke cognition and longer term activities and participation: A systematic review. Neuropsychol Rehabil. 2020;30(2):346-370. doi:10.1080/09602011.2018.1464934

11. Melkas S, Vataja R, Oksala NKJ, et al. Depression-executive dysfunction syndrome relates to poor poststroke survival. Am J Geriatr Psychiatry. 2010;18(11):1007-1016. doi:10.1097/JGP.0b013e3181d695d7

12. Muir RT, Lam B, Honjo K, et al. Trail Making Test elucidates neural substrates of specific poststroke executive dysfunctions. Stroke. 2015;46(10):2755-2761. doi:10.1161/STROKEAHA.115.009936 
medRxiv preprint doi: https://doi.org/10.1101/2021.11.12.21266247; this version posted November 14, 2021. The copyright holder for this

13. Veldsman M, Werden E, Egorova N, Khlif MS, Brodtmann A. Microstructural degeneration and cerebrovascular risk burden underlying executive dysfunction after stroke. Sci Rep. 2020;10(1):17911. doi:10.1038/s41598-020-75074-w

14. Ihle-Hansen H, Thommessen B, Fagerland M, et al. Impact of white matter lesions on cognition in stroke patients free from pre-stroke cognitive impairment: A one-year follow-up study. Dement Geriatr Cogn Disord Extra. 2012;2:38-47. doi:10.1159/000336817

15. Fu JH. Extent of white matter lesions is related to acute subcortical infarcts and predicts further stroke risk in patients with first ever ischaemic stroke. J Neurol Neurosurg Psychiatry. 2005;76(6):793-796. doi:10.1136/jnnp.2003.032771

16. Li L, Simoni M, Küker W, et al. Population-based case-control study of white matter changes on brain imaging in transient ischemic attack and ischemic stroke. Stroke. 2013;44(11):3063-3070. doi:10.1161/STROKEAHA.113.002775

17. Singer OC, Sitzer M, du Mesnil de Rochemont R, Neumann-Haefelin T. Practical limitations of acute stroke MRI due to patient-related problems. Neurology. 2004;62(10):1848. doi:10.1212/01.WNL.0000125320.53244.FA

18. Demeyere N, Riddoch MJ, Slavkova ED, Bickerton WL, Humphreys GW. The Oxford Cognitive Screen (OCS): Validation of a stroke-specific short cognitive screening tool. Psychol Assess. 2015;27(3):883-894. doi:10.1037/pas0000082

19. Demeyere N, Haupt M, Webb SS, et al. Introducing the tablet-based Oxford Cognitive Screen-Plus (OCS-Plus) as an assessment tool for subtle cognitive impairments. Sci Rep. 2021;11(1):8000. doi:10.1038/s41598-021-87287-8

20. Humphreys GW, Duta MD, Montana L, et al. Cognitive function in low-income and lowliteracy settings: Validation of the tablet-based Oxford Cognitive Screen in the health and aging in Africa: A longitudinal study of an INDEPTH Community in South Africa (HAALSI). J Gerontol Ser B. 2017;72(1):38-50. doi:10.1093/geronb/gbw139

21. Reitan RM, Wolfson D. Category test and trail making test as measures of frontal lobe functions. Clin Neuropsychol. 1995;9(1):50-56. doi:10.1080/13854049508402057 
22. Burgess PW, Shallice T. Bizarre responses, rule detection and frontal lobe lesions.

Cortex. 1996;32(2):241-259. doi:10.1016/S0010-9452(96)80049-9

23. Wojciulik E, Rorden C, Clarke K, Husain M, Driver J. Group study of an "undercover" test for visuospatial neglect: Invisible cancellation can reveal more neglect than standard cancellation. J Neurol Neurosurg Psychiatry. 2004;75(9):1356-1358.

doi:10.1136/jnnp.2003.021931

24. Miyake A, Friedman NP, Emerson MJ, Witzki AH, Howerter A, Wager TD. The unity and diversity of executive functions and their contributions to complex "frontal lobe" tasks: A latent variable analysis. Cognit Psychol. 2000;41(1):49-100. doi:10.1006/cogp.1999.0734

25. Rorden C, Bonilha L, Fridriksson J, Bender B, Karnath HO. Age-specific CT and MRI templates for spatial normalization. NeuroImage. 2012;61(4):957-965. doi:10.1016/j.neuroimage.2012.03.020

26. Griffis JC, Metcalf NV, Corbetta M, Shulman GL. Lesion Quantification Toolkit: A MATLAB software tool for estimating grey matter damage and white matter disconnections in patients with focal brain lesions. NeuroImage Clin. 2021;30:102639. doi:10.1016/j.nicl.2021.102639

27. Yeh FC, Panesar S, Fernandes D, et al. Population-averaged atlas of the macroscale human structural connectome and its network topology. NeuroImage. 2018;178:57-68. doi:10.1016/j.neuroimage.2018.05.027

28. Wahlund LO, Barkhof F, Fazekas F, et al. A new rating scale for age-related white matter changes applicable to MRI and CT. Stroke. 2001;32(6):1318-1322. doi:10.1161/01.STR.32.6.1318

29. Simoni M, Li L, Paul NLM, et al. Age- and sex-specific rates of leukoaraiosis in TIA and stroke patients. Neurology. 2012;79(12):1215-1222. doi:10.1212/WNL.0b013e31826b951e

30. Kantarci K, Senjem ML, Avula R, et al. Diffusion tensor imaging and cognitive function in older adults with no dementia. Neurology. 2011;77(1):26-34. doi:10.1212/WNL.0b013e31822313dc 
31. Charlton RA, Schiavone F, Barrick TR, Morris RG, Markus HS. Diffusion tensor imaging detects age related white matter change over a 2 year follow-up which is associated with working memory decline. J Neurol Neurosurg Psychiatry. 2010;81(1):13-19. doi:10.1136/jnnp.2008.167288

32. Bettcher BM, Mungas D, Patel N, et al. Neuroanatomical substrates of executive functions: Beyond prefrontal structures. Neuropsychologia. 2016;85:100-109. doi:10.1016/j.neuropsychologia.2016.03.001

33. Cristofori I, Zhong W, Chau A, Solomon J, Krueger F, Grafman J. White and gray matter contributions to executive function recovery after traumatic brain injury. Neurology. 2015;84(14):1394-1401. doi:10.1212/WNL.0000000000001446

34. Maniega SM, Valdés Hernández MC, Clayden JD, et al. White matter hyperintensities and normal-appearing white matter integrity in the aging brain. Neurobiol Aging. 2015;36(2):909-918. doi:10.1016/j.neurobiolaging.2014.07.048

35. Maillard P, Fletcher E, Harvey D, et al. White matter hyperintensity penumbra. Stroke. 2011;42(7):1917-1922. doi:10.1161/STROKEAHA.110.609768

36. Moore MJ, Demeyere N. Multiverse to inform neurological research: An example using recovery outcome of neglect. J Neurol. Published online May 1, 2021. doi:10.1007/s00415-021-10612-8

37. Fazekas F, Chawluk J, Alavi A, Hurtig H, Zimmerman R. MR signal abnormalities at 1.5 T in Alzheimer's dementia and normal aging. Am J Roentgenol. 1987;149(2):351-356. doi:10.2214/ajr.149.2.351

38. Dancause N. Extensive Cortical Rewiring after Brain Injury. J Neurosci. 2005;25(44):10167-10179. doi:10.1523/JNEUROSCI.3256-05.2005 
medRxiv preprint doi: https://doi.org/10.1101/2021.11.12.21266247; this version posted November 14, 2021. The copyright holder for this preprint (which was not certified by peer review) is the author/funder, who has granted medRxiv a license to display the preprint in perpetuity.

All rights reserved. No reuse allowed without permission.

\section{FIGURES AND TABLES}

Table 1. A breakdown of patient demographic and clinical information.

\begin{tabular}{lc}
\multicolumn{1}{c}{ Demographics } & Statistics \\
\hline Years of age, mean (S.D.) & $73.76(11.72)$ \\
Years of education, mean (S.D.) & $12.74(3.67)$ \\
Scan date (days), mean (S.D.) & $1.04(2.42)$ \\
Stroke volume $\left(\mathrm{cm}^{3}\right.$ ), mean (S.D.) & $45.97(114.75)$ \\
Sex, N & \\
$\quad$ Female & 43 \\
$\quad$ Male & 47 \\
Stroke type, N & \\
Ischaemic & 64 \\
$\quad$ Haemorrhagic & 26 \\
Stroke lateralisation, N & \\
Unilateral left hemisphere & 42 \\
Unilateral right hemisphere & 45 \\
Bilateral* & 3 \\
Stroke location, N & \\
Anterior cerebral artery (ACA) & 3 \\
Middle cerebral artery (MCA) & 64 \\
Posterior cerebral artery (PCA) & 8 \\
Vertebrobasilar & 7 \\
Intraventricular & 3 \\
Multiple territories & 5 \\
\hline
\end{tabular}

*Bilateral stroke was defined as a single stroke crossing the midline.

S.D. = standard deviation. 
medRxiv preprint doi: https://doi.org/10.1101/2021.11.12.21266247; this version posted November 14, 2021. The copyright holder for this preprint (which was not certified by peer review) is the author/funder, who has granted medRxiv a license to display the preprint in perpetuity. All rights reserved. No reuse allowed without permission.

Figure 1. Distribution of scores for the OCS-Plus Trails, Rule Finding, and Selection tasks acquired in the present study. Data from the present study (histograms) are plotted against the mean scores obtained from a normative aging sample (dotted lines).

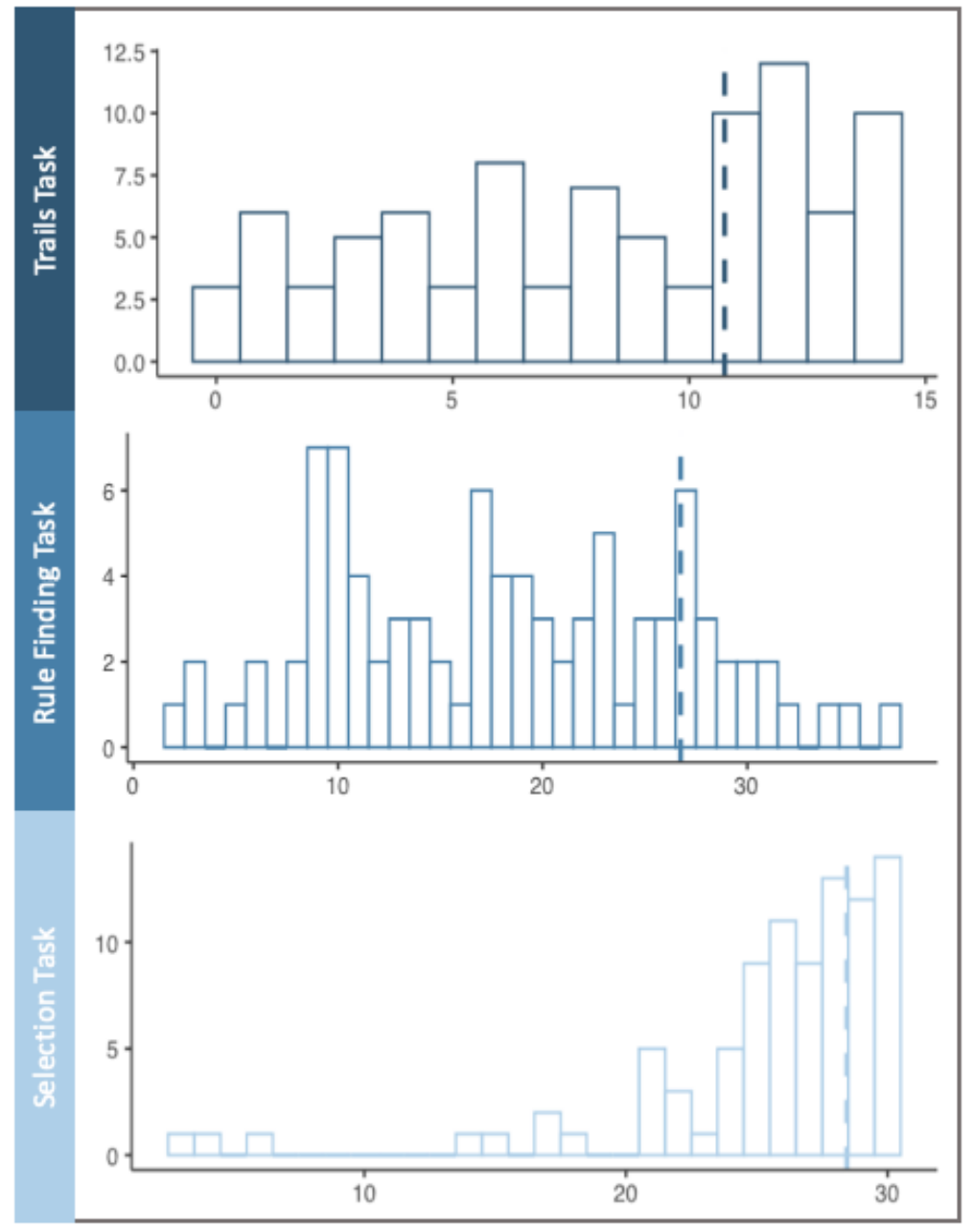

Figure 2. A lesion overlay map of the study sample $(n=86)$, with colour indicating the number of patients with lesions in each area. MNI coordinates of each transverse section (z-axis) are provided.

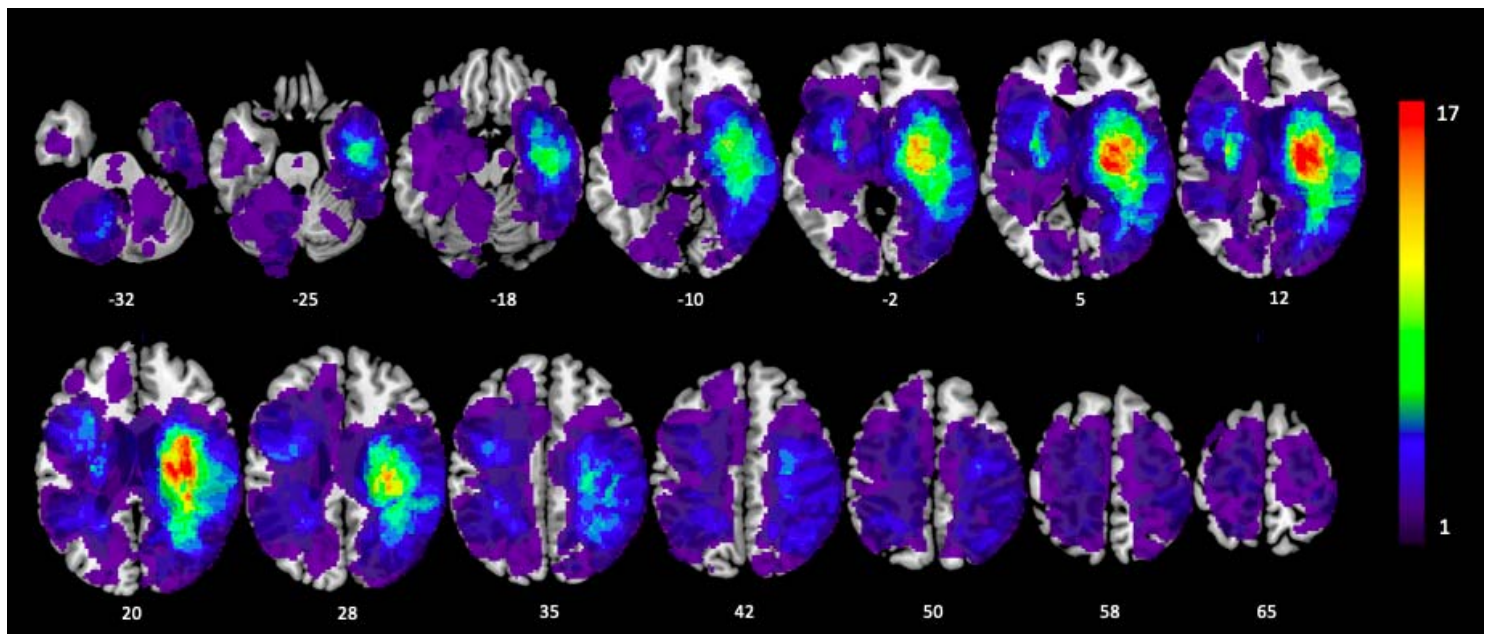


medRxiv preprint doi: https://doi.org/10.1101/2021.11.12.21266247; this version posted November 14, 2021. The copyright holder for this preprint (which was not certified by peer review) is the author/funder, who has granted medRxiv a license to display the preprint in perpetuity.

All rights reserved. No reuse allowed without permission.

Table 2. Descriptive statistics for each ROI from the HCP-842.

\begin{tabular}{|c|c|c|c|c|}
\hline ROI & $n$ & $n \geq 10 \%$ & $\begin{array}{c}\text { Mean (\% } \\
\text { disconnection) }\end{array}$ & S.D. \\
\hline Anterior commissure & 42 & 31 & 24.97 & 37.92 \\
\hline Arcuate fasciculus & 48 & 38 & 18.30 & 21.93 \\
\hline Acoustic radiation & 37 & 31 & 14.62 & 20.73 \\
\hline Cerebellum & 15 & 7 & 2.41 & 7.38 \\
\hline Corpus callosum (anterior) & 33 & 12 & 5.24 & 12.25 \\
\hline Corpus callosum (mid-anterior) & 45 & 24 & 11.80 & 23.62 \\
\hline Corpus callosum (central) & 31 & 23 & 15.16 & 30.04 \\
\hline Corpus callosum (mid-posterior) & 44 & 20 & 15.47 & 31.31 \\
\hline Corpus callosum (posterior) & 61 & 28 & 20.92 & 32.90 \\
\hline Corticospinal tract & 59 & 42 & 20.13 & 22.32 \\
\hline Corticostriatal tract & 72 & 33 & 10.87 & 12.71 \\
\hline Central tegmental tract & 10 & 9 & 5.94 & 19.52 \\
\hline Corticothalamic pathway & 75 & 38 & 13.31 & 16.00 \\
\hline Cingulum & 31 & 16 & 5.81 & 12.82 \\
\hline Dorsal longitudinal fasciculus & 9 & 9 & 6.88 & 22.18 \\
\hline Extreme capsule & 46 & 40 & 20.20 & 22.37 \\
\hline Frontal aslant tract & 32 & 28 & 9.64 & 15.68 \\
\hline Frontopontine tract & 53 & 40 & 18.20 & 20.96 \\
\hline Fornix & 16 & 15 & 8.65 & 22.40 \\
\hline Inferior cerebellar penducle & 10 & 10 & 4.82 & 14.61 \\
\hline Inferior fronto-occipital fasciculus & 49 & 37 & 17.80 & 22.81 \\
\hline Inferior longitudinal fasciculus & 34 & 22 & 9.82 & 18.22 \\
\hline Lateral lemniscus & 6 & 6 & 3.01 & 11.29 \\
\hline Middle cerebellar peduncle & 12 & 8 & 3.33 & 10.77 \\
\hline Medial longitudinal fasciculus & 6 & 5 & 4.57 & 18.87 \\
\hline Medial lemniscus & 21 & 19 & 9.27 & 17.87 \\
\hline Middle longitudinal fasciculus & 33 & 28 & 15.20 & 22.16 \\
\hline Occipitopontine tract & 40 & 33 & 16.98 & 22.37 \\
\hline Optic radiation & 32 & 25 & 12.80 & 21.59 \\
\hline Posterior commissure & 14 & 7 & 7.25 & 25.57 \\
\hline Parietopontine tract & 53 & 36 & 18.02 & 21.45 \\
\hline Reticulospinal tract & 7 & 7 & 3.22 & 12.32 \\
\hline Superior cerebellar peduncle & 29 & 16 & 9.82 & 20.76 \\
\hline Superior longitudinal fasciculus & 38 & 25 & 10.35 & 16.51 \\
\hline Spinothalamic tract & 24 & 22 & 9.29 & 17.38 \\
\hline Temporopontine tract & 35 & 31 & 15.81 & 22.04 \\
\hline Uncinate fasciculus & 24 & 14 & 7.36 & 16.04 \\
\hline U-fibers & 61 & 21 & 7.54 & 10.25 \\
\hline Vermis & 10 & 9 & 8.24 & 25.77 \\
\hline Vertical occipital fasciculus & 14 & 10 & 4.52 & 12.70 \\
\hline
\end{tabular}

$n=$ number of patients with any ROI disconnection. $n \geq 10 \%=$ number of patients with at least $10 \%$ ROI disconnection. S.D. = standard deviation. 
medRxiv preprint doi: https://doi.org/10.1101/2021.11.12.21266247; this version posted November 14, 2021. The copyright holder for this preprint (which was not certified by peer review) is the author/funder, who has granted medRxiv a license to display the preprint in perpetuity.

All rights reserved. No reuse allowed without permission.

Figure 3. Relationship between leukoaraiosis and the composite executive function score. The means and standard deviations are plotted (in black) along with individual patient scores (points).

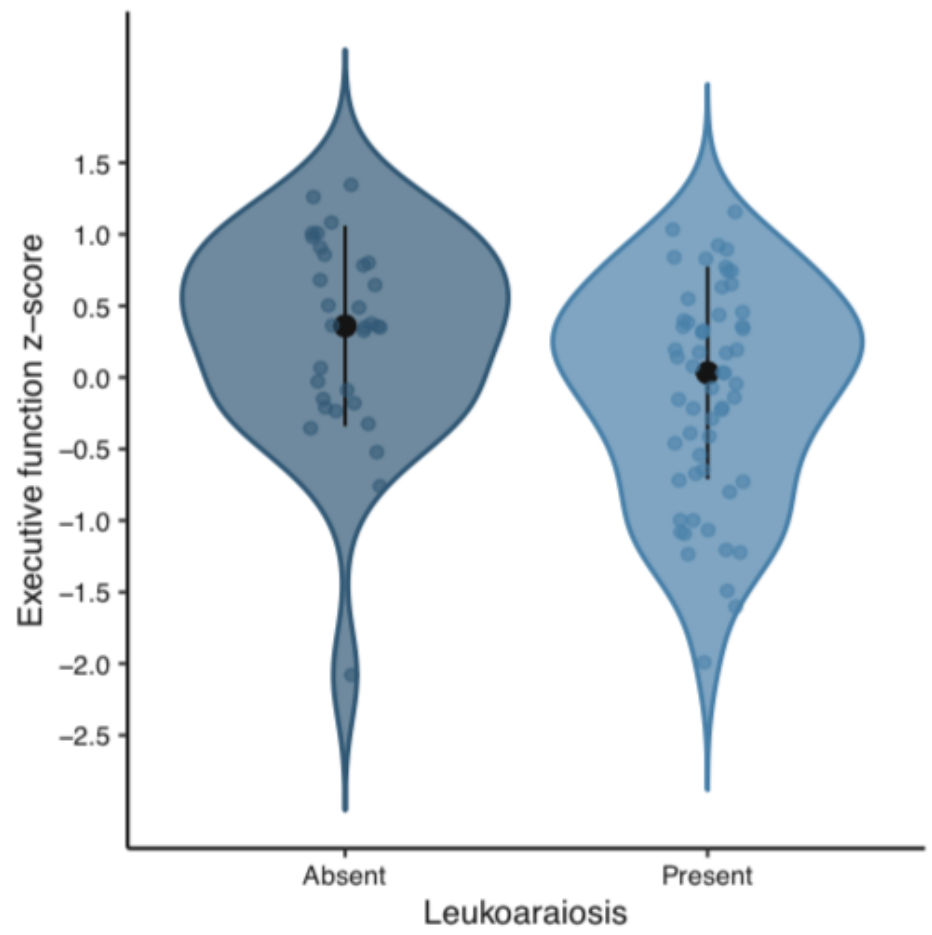

